\section{Federally Assisted Housing Standards for Blood Lead Levels Aligned with CDC-Recommended Threshold}

On January 13, 2017, the U.S. Department of Housing and Urban Development (HUD) lowered the threshold of lead in young children's blood that triggers interventions to evaluate and control exposure hazards from $20 \mu \mathrm{g} / \mathrm{dL}$ to $5 \mu \mathrm{g} / \mathrm{dL}$, matching the reference level used by CDC (1). The rule includes a process to continue HUD alignment with any future updates to CDC's reference level (1).

There is no known safe level of childhood lead exposure (2). Lead exposure can affect nearly every body system (2). Even low blood lead levels can damage a child's brain and nervous system, slow growth and development, cause hearing and speech problems, and affect intelligence quotient (IQ), academic achievement, and behavior (3). Lead poisoning also places a social and economic burden on families, communities, and the nation, estimated at \$192-270 billion over the lifetime of the cohort of U.S. children aged $\leq 6$ years (3). Lead control programs are highly cost effective: for every dollar spent, \$17-\$221 is returned in health benefits, increased IQ, higher lifetime earnings and tax revenue, reduced spending on special education, and reduced criminal activity (3).

Despite significant reductions in lead poisoning over the last several decades, homes remain the primary sources of childhood lead exposure. Approximately 24 million U.S. homes contain deteriorated lead-based paint and lead-contaminated house dust (4); even conservative estimates suggest that $>535,000$ children aged $<5$ years have blood lead levels high enough to damage their health (5). HUD estimates that 57,000 housing units affected by the rule have lead-based paint hazards and are occupied by children aged $<6$ years (G).

Additional information about childhood lead poisoning prevention is available at https://www.cdc.gov/nceh/lead/.

${ }^{1}$ Office of Policy, Planning, and Partnerships, National Center for Environmental Health, CDC.

Corresponding author: Jared B. Fox, jaredfox@cdc.gov, 404-639-7620.

\section{References}

1. Office of the Secretary, US Department of Housing and Urban Development. Requirements for notification, evaluation and reduction of lead-based paint hazards in federally owned residential property and housing receiving federal assistance; response to elevated blood lead levels. Final rule. Fed Regist 2017;82:4151-72.

2. CDC; Advisory Committee on Childhood Lead Poisoning Prevention. Low level lead exposure harms children: a renewed call for primary prevention. Atlanta, GA: US Department of Health and Human Services, CDC, Advisory Committee on Childhood Lead Poisoning Prevention; 2012. https://www. cdc.gov/nceh/lead/ACCLPP/Final_Document_030712.pdf

3. Gould E. Childhood lead poisoning: conservative estimates of the social and economic benefits of lead hazard control. Environ Health Perspect 2009;117:1162-7. http://dx.doi.org/10.1289/ehp.0800408

4. US Department of Housing and Urban Development. National survey of lead and allergens in housing, volume I, revision 7.1: analysis of lead hazards. Washington, DC: US Department of Housing and Urban Development; 2002.

5. Wheeler W, Brown MJ. Blood lead levels in children aged 1-5 yearsUnited States, 1999-2010. MMWR Morb Mortal Wkly Rep 2013;62:245-8.

6. Office of Lead Hazard Control and Healthy Homes, US Department of Housing and Urban Development. Requirements for notification, evaluation and reduction of lead-based paint hazards in federally owned residential property and housing receiving federal assistance; response to elevated blood lead levels. Fed Regist 2016;81:60304-29. 


\section{Release of National Association of State Public Health Veterinarians' 2016 Compendium of Animal Rabies Prevention and Control}

The 2016 Compendium of Animal Rabies Prevention and Control was released in the March 1, 2016 issue of the Journal of the American Veterinary Medical Association (1). The Compendium's national recommendations for the prevention and control of animal rabies are intended to serve as a basis for an effective rabies control program in the United States. These recommendations facilitate standardization of control procedures across jurisdictions and are reviewed annually and updated as necessary. This announcement of the recommendations facilitates their adoption by increasing awareness among public health agencies and practitioners and makes more readily available a link to statutes and regulations in certain jurisdictions that refer directly to the Compendium language published in $M M W R$.

The 2016 Compendium is an update and supersedes recommendations made in previous versions (2). Several modifications were made, including explicit encouragement of interdisciplinary approaches to rabies control, recommendations to collect and report additional data elements on rabid domestic animals to the national level, and updates to the list of marketed animal rabies vaccines.

The 2016 Compendium also includes important changes to the recommended management of dogs and cats exposed to rabies and a reduction of the recommended quarantine period for certain species. These recommendations are based on a combination of research indicating rapid and robust anamnestic response to booster doses of rabies vaccine, observational evidence of rabies incubation periods in exposed dogs and cats, and expert opinion. These particular recommendations are as follows: 1) dogs and cats that have never been vaccinated should either be euthanized immediately or vaccinated within 96 hours of the exposure and placed in strict quarantine for 4 months (a reduction from 6 months in previous recommendations); 2) dogs and cats that are overdue for a booster vaccination (and have appropriate documentation of prior rabies vaccination) should receive a booster vaccination within 96 hours of rabies exposure and be kept under owner observation for 45 days; and 3) dogs and cats that are overdue for booster vaccination (and do not have documentation of prior vaccination) may be treated as unvaccinated or undergo serologic monitoring to document an anamnestic response after receipt of a rabies booster vaccination.

\section{References}

1. Brown CM, Slavinski S, Ettestad P, Sidwa TJ, Sorhage FE; National Association of State Public Health Veterinarians; Compendium of Animal Rabies Prevention and Control Committee. Compendium of animal rabies prevention and control, 2016. J Am Vet Med Assoc 2016;248:505-17. http://dx.doi.org/10.2460/javma.248.5.505

2. Brown CM, Conti L, Ettestad P, Leslie MJ, Sorhage FE, Sun B. Compendium of animal rabies prevention and control, 2011. J Am Vet Med Assoc 2011;239:609-17. http://dx.doi.org/10.2460/javma.239.5.609 


\section{Vol. 66 , No. 4}

In the cover box "National Black HIV/AIDS Awareness Day - February 7, 2017," on page 97, the second sentence of the second paragraph should have read, "Among blacks living with diagnosed HIV infection in 2013, 54\% were retained in care (two or more CD4 or viral load tests $\geq 3$ months apart) and $49 \%$ had a suppressed viral load ( $<200$ copies/mL at most recent test) (2)." 